\title{
FORMAÇÃO E CONSTRUÇÃO DA DOCÊNCIA NA EDUCAÇÃO INFANTIL
}

\author{
Jaqueline Paschoal ${ }^{1}$, Sonara Maria Lopes de Oliveira ${ }^{2}$, Marta Regina Furlan de Oliveira ${ }^{3}$. \\ ${ }^{1}$ Doutora em Educação pela Universidade Estadual de Maringá - UEM, PR. Professora titular da Universidade Estadual \\ de Londrina, PR. ORCID iD: https://orcid.org/0000-0002-7961-2362 E-mail: jaquelinedelgado@uol.com.br \\ ${ }^{2}$ Mestre em Educação pela Universidade Estadual de Londrina - UEL, PR. Coordenadora Pedagógica da Educação \\ Infantil e Anos Iniciais do Colégio Mãe de Deus da cidade de Londrina, PR, ORCID iD: https://orcid.org/0000-0002- \\ 6660-8372. E-mail: irsonaramaria@hotmail.com \\ ${ }^{3}$ Pós-Doutora em Educação pela Universidade Estadual Paulista - UNESP, Doutora em Educação pela Universidade \\ Estadual de Maringá - UEM. Docente do Departamento de Educação e do Programa de Pós-Graduação em Educação - \\ Mestrado e Doutorado junto à Universidade Estadual de Londrina - UEL, PR. ORCID iD: https://orcid.org/0000-0002- \\ 2188-1260. E-mail: marta.furlan@yahoo.com.br
}

\section{RESUMO}

Este estudo de caráter bibliográfico tem o propósito de discutir as especificidades da docência na Educação Infantil a partir das origens, determinações legais e formação profissional. A aprovação da Lei de Diretrizes e Bases de 1996 reconhece a Educação Infantil como primeira etapa da Educação Básica, visto que a criança é considerada cidadã, sujeito de direitos, desde a promulgada da Constituição Federal em 1988. Apesar dos inúmeros progressos das leis em relação ao direito à educação desde o nascimento, muitos são os desafios que se coloca. Isso porque a efetivação desse direito, ainda não está acessível a todas as crianças, principalmente quando se considera os quesitos: acesso, permanência e qualidade dos serviços prestados. Tal fato ocorre porque, em muitos casos, há: precariedade na formação dos professores, nas condições de trabalho e na atuação dos docentes. Daí a importância da garantia e implementação de políticas públicas de formação inicial e continuada que possibilitem aos professores a construção de práticas que reconheçam as especificidades desse nível de ensino. A valorização profissional em termos de salário e quadro de carreira, também contribui para a melhoria das práticas educativas junto às crianças, sobretudo no desenvolvimento de suas diferentes linguagens.

Palavras-chave: História; Docência; Formação; Atuação; Legislação.

\section{TRAINING AND CONSTRUCTION OF TEACHING IN CHILDHOOD EDUCATION}

\section{ABSTRACT}

This bibliographic study aims to discuss the specificities of teaching in Early Childhood Education from its origins, legal determinations and professional training. The approval of the 1996 Law of Guidelines and Bases recognizes Early Childhood Education as the first stage of Basic Education, since the child is considered a citizen, subject of rights, since the enactment of the Federal Constitution in 1988. Despite the innumerable progress of laws in Regarding the right to education from birth, there are many challenges. This is because the realization of this right is not yet accessible to all children, especially when considering the questions: access, permanence and quality of services provided. This fact occurs because, in many cases, there are: precariousness in teacher training, in working conditions and in the performance of teachers. Hence the importance of guaranteeing and implementing public policies for initial and continuing education that enable teachers to build practices that recognize the specificities of this level of education. The professional valorization in terms of salary and career, also contribute to the improvement of educational practices with children, especially in the development of their different languages.

Keywords: History; Teaching; Formation; Performance; Legislation.

\section{FORMACIÓN Y CONSTRUCCIÓN DE LA ENSEÑANZA EN LA EDUCACIÓN INFANTIL}




\section{RESUMEN}

Este estudio bibliográfico tiene como objetivo discutir las especificidades de la enseñanza en la Educación Infantil desde sus orígenes, determinaciones legales y capacitación profesional. La aprobación de la Ley de Pautas y Bases de 1996 reconoce la Educación de la Primera Infancia como la primera etapa de la Educación Básica, ya que el niño es considerado ciudadano, sujeto de derechos, desde la promulgación de la Constitución Federal en 1988. A pesar del innumerable progreso de las leyes En cuanto al derecho a la educación desde el nacimiento, existen muchos desafíos. Esto se debe a que la realización de este derecho aún no es accesible para todos los niños, especialmente al considerar las preguntas: acceso, permanencia y calidad de los servicios prestados. Este hecho ocurre porque, en muchos casos, existen: precariedad en la formación del profesorado, en las condiciones de trabajo y en el desempeño de los docentes. De ahí la importancia de garantizar e implementar políticas públicas de educación inicial y continua que permitan a los maestros desarrollar prácticas que reconozcan las especificidades de este nivel de educación. La valorización profesional en términos de salario y carrera, también contribuye a la mejora de las prácticas educativas con los niños, especialmente en el desarrollo de sus diferentes idiomas.

Palabras- clave: Historia; Enseñando; Formación; Actuación; Legislación.

\section{INTRODUÇÃO}

A formação para a docência na Educação Infantil é um tema que tem ocupado lugar no cenário atual, visto que essa etapa da Educação Básica se consolida como espaço importante e necessário na educação e nos cuidados das crianças até cinco anos de idade. Discutir sobre os processos formativos dos professores, é antes de tudo compreender como tem se constituído historicamente 0 trabalho pedagógico com crianças com vistas a superação das práticas espontaneístas e assistenciais, sobretudo para àquelas das classes menos favorecidas. Isso porque, do ponto de vista histórico, segundo Paschoal (2018) a educação da criança em espaços coletivos, esteve à margem do sistema educacional brasileiro desde a sua origem.

Por outro lado, desde a provação da Constituição Federal de 1988, legitimada pela Lei de Diretrizes e Bases de 1996, que determinou a inserção da Educação Infantil como primeira etapa da Educação Básica, pode-se afirmar que essa instituição consolidou-se como espaço pedagógico e tem o objetivo de proporcionar condições adequadas para o desenvolvimento de seu bem-estar e a ampliação de suas experiências.

Paschoal e Brandão (2015) reconhecem o avanço da LDB (1996) quanto à exclusão de professores leigos do sistema de ensino e a determinação da formação em nível superior, em cursos de licenciatura, de graduação plena, ainda que admitida como formação mínima para o exercício do magistério na Educação Infantil e nos cinco primeiros anos do ensino fundamental, a modalidade normal.

Na percepção de Cerisara (2002, p. 25), apesar dos avanços das prescrições legais, a formação para a docência na Educação Infantil se constitui um campo em construção, pois "tentar traçar o perfil desses profissionais significa considerá-las em seu contexto sociocultural, incluindo também as contradições sociais como as oposições de gênero, raça, idade e classe social” (CERISARA, 2002, p. 25). Nesse sentido, o objetivo desse estudo de caráter bibliográfico é discutir as especificidades da docência na Educação Infantil a partir das origens, determinações legais e formação profissional.

Acredita-se que a dupla trajetória do trabalho desenvolvido nas creches e pré-escolas, acabou por gerar identidades profissionais também distintas em atuação no mesmo campo profissional (HADDAD; CORDEIRO; MÔNACO, 2012). Além disso, a ausência de consenso, associada à falta de clareza quanto ao perfil profissional "deve-se tanto a fatores externos, relacionados com a origem e o desenvolvimento das instituições de cuidado e educação da criança pequena, quanto a fatores inerentes às atividades voltadas à infância" (HADDAD; CORDEIRO; MÔNACO, 2012, p. 136).

No entendimento de Haddad; Cordeiro e Mônaco (2012, p 137), a desvalorização das "ocupações diretamente associadas ao universo feminino em contraposição ao que se convencionou chamar de universo masculino de trabalho, geralmente identificado com o espaço público, em que as relações de impessoalidade 
predominam", também contribuiu para reforçar o papel reprodutivo da mulher no campo profissional.

Nessa perspectiva, Angotti (2006) chama a atenção para a superação dos antigos conceitos e de se considerar a infância enquanto etapa singular da vida do ser humano, que deve ser respeitada. A autora defende a prática de "um cuidar que promova a educação, e de uma educação que não deixe de cuidar da criança, de atendê-la em suas necessidades e exigências essenciais, desde a sua mais tenra idade em atividades, espaços e tempos de ludicidade" (ANGOTTI, 2006, p. 19). Uma das dimensões desafiadoras neste cenário capitalista é evidenciar o trabalho coletivo, e intencionalmente pedagógico de seus profissionais no sentido de garantir a qualidade dos serviços prestados.

As pesquisas de Campos (2013, p. 24) sobre a qualidade dos sistemas de ensino na América Latina indicam que o discurso da qualidade encobre a luta pelo acesso à educação, visto que "as organizações escolares contribuíram para a reprodução da estrutura social, muito mais por meio de processos de exclusão do que por mecanismos internos de reforço da desigualdade". Exclusão que se acentua nos grupos marginalizados da população, principalmente nas regiões rurais e nas periferias pobres das grandes cidades.

Tratar da qualidade, para Campos (2013), pressupõe levar em consideração não só a desigualdade de oportunidades educacionais, os processos de exclusão social vividos dentro e fora da escola e as contradições entre os objetivos econômicos e as metas das políticas educacionais. Segundo a autora, "a expansão horizontal e vertical dos sistemas escolares reflete as características de desigualdade da sociedade, já que não é a mesma educação que chega a todos" (CAMPOS, 2013, p. 25). Ao contrário, a qualidade depende em muito das condições econômicas dos diferentes grupos sociais.

Outros aspectos que contribuem para a precarização do atendimento, segundo Campos, Fullgraf e Wiggers (2006), diz respeito às condições precárias de funcionamento, falta de materiais pedagógicos, a ausência de projetos pedagógicos, a baixa escolaridade dos professores e a dificuldade na comunicação com as famílias.
Daí a importância do debate, pois o reconhecimento de que ser professor é uma profissão, "que não basta ter dom, mas, sim, que são imprescindíveis conhecimentos e engajamento político para lutar por melhorias para a categoria profissional" (MASSUCATO; AZEVEDO, 2012, p. 153). Daí o desafio de consolidar, efetivamente, não só os direitos no âmbito educativo, mas garantir todos os outros previstos nas leis para todas as crianças brasileiras. É fundamental não se perder de vista as conquistas e os avanços na história da Educação Infantil nos últimos trinta anos, já que, para Flores e Albuquerque (2016, p.105), “a fragilidade na concepção de Educação Infantil, a despeito dos documentos legais que afirmam este direito, pode ser o elemento principal que devemos enfrentar, com a proposição de situações promotoras da reflexão e estudo".

Para uma melhor organização da exposição, o estudo de caráter bibliográfico, divide-se em duas seções. A primeira aborda o percurso histórico da formação de professores no Brasil, bem como os avanços e retrocessos da legislação que determinam os processos formativos desses profissionais. A segunda discute a construção da docência na Educação Infantil a partir das especificidades do trabalho pedagógico com as crianças. $O$ intuito é apontar os inúmeros desafios colocados para a consolidação dessa etapa da educação básica como espaço de formação da criança e de seus profissionais.

\section{ASPECTOS HISTÓRICOS DA FORMAÇÃO DE PROFESSORES NO BRASIL}

Ao se compreender a escola como espaço privilegiado para a promoção da infância e de seus direitos e peculiaridades, e se discorrer sobre a importância de uma prática pedagógica qualificada, é imprescindível que se analise a estrutura dos cursos de formação e os pontos fundamentais que revelam os motivos pelos quais a busca por caminhos que garantam um nível de excelência na formação profissional dos professores, ainda não tenha sido concluída.

Do ponto de vista histórico, a preocupação com a formação de professores surgiu, mais especificamente, após a independência do país. No ano de 1835 , seguindo uma tendência vigente em países europeus, foi instituída a primeira Escola Normal do país, em Niterói, no Rio de Janeiro, com a incumbência de formar professores para as escolas primárias 
(SAVIANI, 2009). Nos anos subsequentes, escolas como essa surgiram em distintos estados do Brasil. Saviani (2009, p. 144) esclarece que "essas escolas, entretanto, tiveram existência intermitente, sendo fechadas e reabertas periodicamente", além disso, durante muitos anos, essa e outras instituições de formação de professores, em articulação com as transformações que aconteceram na sociedade brasileira, passaram por inúmeras reformulações e alterações, em nível de métodos e organizações (SAVIANI, 2009).

Não obstante a criação de outras instituições no decorrer dos anos, como os Institutos de Educação, os cursos de Pedagogia e Licenciatura e os Institutos Superiores de Educação, as Escolas Normais foram responsáveis pela formação de professores para o ensino primário até o ano de 1971. Nesse ano, a Lei 5.692/71 alterou a nominação dos ensinos Primário e Médio para Primeiro e Segundo Graus, respectivamente, e instituiu o "curso de segundo grau unificado, de caráter profissionalizante, albergando, ao menos como possibilidade, um leque amplo de habilitações profissionais" (SAVIANI, 2005, p. 18).

A Lei 5.692/71 determinou, em seu artigo 30 , a exigência de habilitação específica de 2 은 grau como formação mínima para o exercício do magistério no ensino de 10 grau, da $1 \underline{\text { a à }} 4 \underline{a}$ séries (BRASIL, 1971). Nesse momento, foi estabelecida a HEM - Habilitação Específica de 20 grau para o exercício do Magistério. Essa lei determinou, ainda, a formação em grau superior, em nível de graduação, para a atuação no ensino de $5 \underline{a}$ à $8 \underline{a}$ séries e de 20 grau. Em seu artigo 33, determinou que a "formação de administradores, planejadores, orientadores, inspetores, supervisores e demais especialistas de educação será feita em curso superior de graduação, com duração plena ou curta, ou de pós-graduação" (BRASIL, 1971).

Ao se referir à instituição da HEM em substituição às Escolas Normais, Saviani (2005, p.20) considera que "a formação de professores para o antigo ensino primário foi, pois, reduzida a uma habilitação dispersa em meio a tantas outras, configurando um quadro de precariedade bastante preocupante". Diante de problemas e deficiências identificados na estrutura da HEM, o Ministério da Educação desenvolveu o projeto CEFAM (Centros de Formação e aperfeiçoamento do Magistério) com caráter de revitalização da Escola Normal. Segundo Saviani (2005, p. 21), o projeto teve resultados significativos, porém não teve continuidade.

A década de 1980 contou com importantes movimentos de reformulação e avanços no que se refere à educação no país. Nesse sentido, Saviani (2009, p. 148) assinala que a partir daí "a maioria das instituições tendeu a situar como atribuição dos cursos de Pedagogia a formação de professores para a Educação Infantil e para as séries iniciais do ensino de 10 grau". Tais movimentos culminaram com a promulgação da LDB 9.394, em 1996, que determina, em seu artigo 62 , que a formação de professores para a educação básica se daria em nível superior, "admitida, como formação mínima para o exercício do magistério na Educação Infantil e nos cinco primeiros anos do Ensino Fundamental, a oferecida em nível Médio, na modalidade Normal" (BRASIL, 1996).

No que se refere ao desenvolvimento histórico e legal do processo de formação de professores no Brasil, pode-se destacar algumas observações importantes. A primeira delas é o fato de que, desde os primórdios, a formação de professores para o trabalho com as crianças menores, em nosso país, foi pensada em nível elementar. Esse fato pode ser observado já em 1971, quando a Lei 5.692/71 determina a formação em nível superior para a atuação no ensino de 5a a 8 a séries e de $2^{\circ}$ grau, bem como, para administradores, planejadores, orientadores, inspetores, supervisores e demais especialistas de educação, ou seja, apenas aos professores das primeiras quatro séries do primeiro grau não foi exigida uma formação em nível superior. Outro fato importante que se constata ao se analisar essa lei é que, como a educação de crianças menores de cinco anos não é mencionada, também a formação para professores dessa etapa foi inexistente até então.

Posteriormente, embora a LDB 9394/96 tenha confirmado a formação em nível superior em cursos de licenciatura plena para toda a educação básica, ela admite, no mesmo artigo, que a formação mínima para o exercício do magistério na Educação Infantil e nos Anos Iniciais seja em nível Médio, na modalidade Normal. Para Saviani $(2005$, p. 22), "o espírito da nova LDB (1996) era considerar o nível superior como exigência para a formação de professores de todos os tipos", pois tal iniciativa elevaria o preparo dos professores do Brasil, todavia "as esperanças depositadas na nova Lei de Diretrizes e Bases da Educação Nacional, no sentido de que 
ela viesse a enfrentar com êxito o problema da formação de professores, resultaram frustradas" (SAVIANI, 2005, p. 25).

Sobre essa questão, Gatti (2010, p. 1358) explica que, "historicamente, nos cursos formadores de professores esteve desde sempre colocada a separação formativa entre professor polivalente - Educação Infantil e primeiros anos do Ensino Fundamental - e professor especialista". A autora ressalta que a própria legislação criou, ao longo dos anos, essa distinção entre as duas categorias de professores, o que gerou a ideia de um valor social menor para o professor polivalente, responsável pela Educação Infantil e Anos Iniciais, e maior para o professor especialista, responsável pelas demais séries.

A dessemelhança realmente se dá, segundo Gatti (2010, p. 1358), "nos cursos, nas carreiras e salários, nas representações da comunidade social, da academia e dos políticos, mesmo com a atual exigência de formação em nível superior dos professores dos primeiros anos da Educação Básica". A autora atribui a esse fato a dificuldade de inovação na estrutura de instituições e cursos de formação de professores para o início da Educação Básica, uma vez que a representação, historicamente constituída, não permite ponderações e reestruturações para essa formação.

Sobre essa questão, Saviani (2009) afirma que, embora as políticas formativas tenham sofrido contínuas mudanças, devido à sua precariedade não conseguiram "estabelecer um padrão minimamente consistente de preparação docente para fazer face aos problemas enfrentados pela educação escolar em nosso país" (SAVIANI, 2009, p. 148). O autor identifica a existência de dois modelos de formação: o primeiro tem como foco conteúdos culturaiscognitivos, que priorizam a cultura geral e o domínio específico de conteúdos da área de conhecimento em que o professor irá lecionar; e o segundo aborda conteúdos pedagógicodidáticos que valorizam o efetivo preparo pedagógico-didático do profissional.

Saviani (2009) ressalta que o problema pode estar situado na dicotomia entre dois aspectos indissociáveis da função docente: forma e conteúdo, ou seja, o que ensinar e como ensinar. Nesse sentido, dois aspectos devem ser observados: por um lado, espera-se que a base de cultura geral clássica e científica, obtida nos cursos de nível médio, auxilie os futuros professores, nos cursos formativos de nível superior, a adquirirem um preparo profissional bem mais consistente, alicerçado em uma sólida cultura pedagógica, segundo o autor.

Por outro lado, entretanto, há o risco de que essa formação seja neutralizada pela força do modelo baseado em conteúdos culturaiscognitivos, o que tenderia a secundarizar as exigências pedagógicas. Nesse contexto, os novos professores teriam "grande dificuldade de atender às necessidades específicas das crianças pequenas, tanto no nível da chamada Educação Infantil como das primeiras séries do ensino fundamental." (SAVIANI, 2009, p. 150). Além disso, Saviani (2009) argumenta que a formação e a atuação de professores devem estar atreladas às condições de trabalho, principalmente, em relação às questões de salário e jornada de trabalho. Para ele, "as condições precárias de trabalho, não apenas neutralizam a ação dos professores, mesmo que estes sejam bem formados" (SAVIANI, 2009, p. 153), pois não é possível garantir uma formação consistente sem recursos financeiros suficientes.

Saviani $(2009$, p. 153) reconhece que as políticas governamentais que defendem a educação e sua importância na sociedade, na realidade "se pautam pela busca da redução de custos, cortando investimentos. Faz-se necessário ajustar as decisões políticas ao discurso imperante" (SAVIANI, 2009, p. 153). Para isso, Freitas (2007, p. 1204) defende uma política de formação e valorização de professores "que contemple de forma articulada e prioritária a formação inicial, formação continuada e condições de trabalho, salários e carreira, com a concepção sócio-histórica do educador a orientála". Entretanto, aponta a dificuldade de sua materialização em uma organização social desigual e excludente como a nossa, que "nos permite entender e atuar no campo das contradições e evita que possamos cair na armadilha das soluções fáceis, ágeis e de menor custo, que caracterizam, via de regra, as iniciativas no âmbito da educação e da formação" (FREITAS, 2007, p. 1220).

A defesa de Freitas (2007) é pela expansão da escolarização e do papel do Estado na disponibilização de recursos financeiros que garantam a expansão da educação superior pública, presencial e de qualidade, sobretudo no que tange aos processos formativos de professores. A autora destaca algumas perspectivas de trabalho no sentido de contribuir para o estabelecimento de uma política global de 
formação mais emancipadora e menos fragmentada, sendo: uma ação conjunta entre as universidades e demais instâncias formadoras e os sistemas de ensino; revisão das estruturas das instituições formadoras para todos os níveis de ensino e fortalecimento de fóruns coletivos de debate e indicação de políticas de formação e valorização profissional (FREITAS, 2007).

Nesse sentido, pode-se considerar que, apesar de a LDB, de 1996, permitir a formação em nível Médio para os professores de Educação Infantil, o simples fato de haver uma determinação legal em relação a isso já representou grande avanço, pois, até então, a educação de crianças pequenas não havia sido reconhecida em nosso país, bem como a formação de seus profissionais.

\section{AS ESPECIFICIDADES DA FORMAÇÃO E ATUAÇÃO DA DOCÊNCIA NA EDUCAÇÃO INFANTIL}

A Educação Infantil e, de modo particular, a creche, foi concebida historicamente como serviço assistencial, voltado apenas aos cuidados da criança, assim, a concepção de que, para exercer essa atividade não seria necessário um preparo profissional, perdurou durante muitos anos. Segundo Arce (2001, p. 168), esses fatores desencadearam desprestígio a esse profissional, cuja função era compreendida, principalmente, pelo cuidado e proximidade com o corpo da criança, como aquela que requer apenas "jeitinho e gostar", por parte de quem a exerce. Desse modo, compreende-se a desqualificação sustentada ao longo de tantos anos para a educação de zero a cinco anos de idade.

A concepção do professor de Educação Infantil ainda traz outro aspecto marcante, ou seja, o fato de a profissão ser exercida, quase em sua totalidade, por mulheres. Para Arce (2001, p. 167), isso se dá pelo fato de que, historicamente, foi consolidada "a imagem do profissional dessa área como sendo da mulher naturalmente educadora, passiva, paciente, amorosa, que sabe agir com bom senso, é guiada pelo coração, em detrimento da formação profissional". Isso corrobora a ideia de que a profissão não necessita de formação ou de que esta pode ser mínima, o que justifica a concepção equivocada, que perdura até os dias atuais, no que concerne, segundo Arce (2001, p. 167), à "não valorização salarial, a inferioridade perante os demais docentes, a vinculação do seu trabalho com o doméstico".
A vinculação da figura feminina e maternal à profissão é definida por Arce (2001, p. 169) como "mito", por se tratar de algo socialmente construído. Essa ideia se faz ainda presente, atualmente, em muitas instituições, nas quais "predomina a utilização de termos como "professorinha" ou "tia", que configuram uma caracterização pouco definida da profissional, oscilando entre $O$ papel doméstico de mulher/mãe e o trabalho de educar" (ARCE, 2001, p. 173). A autora observa, nessa associação ambígua entre o doméstico e o científico, um motivo para a desvalorização do profissional, de modo que "junto com o ambiente e seu mobiliário essa mulher deve-se colocar simplesmente como algo a mais a auxiliar o desenvolvimento infantil" (ARCE, 2001, p. 174).

Sobre essa questão, Batista e Rocha (2018) explicam que "a variedade de funções envolvidas nas ações dos professores, assim como certa indefinição das categorias profissionais, derivam das origens e trajetórias distintas destas instituições", sobretudo no que tange às diferentes formas de atendimento. Para as autoras, o fato de desenvolverem práticas semelhantes à da família em relação à educação e aos cuidados das crianças, "ainda ocasiona tensões no que diz respeito à influência das experiências maternas e domésticas no contexto educacional-pedagógico, dificultando a consolidação de uma cultura própria e específica da profissão" (BATISTA; ROCHA, 2018, p. 96).

Batista e Rocha (2018, p. 97) argumentam ainda que, esta etapa da Educação Básica depende de melhores definições de suas funções, "o que exige pensar a ação docente em uma perspectiva mais ampla, visto que a constituição profissional apresenta hiatos no que diz respeito ao que lhe é próprio e particular". De fato, a realização de atividades relacionadas ao cuidado das crianças pequenas pode ser facilmente associada ao papel de mãe, tia ou babá, entretanto, Rodrigues (2017) destaca a intencionalidade do professor como fator que assinala sua atuação profissional e a distância do cuidar materno. Para a autora "ao mesmo tempo em que se aproxima, o papel docente se afasta do de "mãe" ao articular em outro nível as dimensões de cuidado e de educação que marcam as singulares necessidades desta etapa da vida da criança" (RODRIGUES, 2017, p. 333).

Assim, a intencionalidade do professor e a indissociabilidade do cuidar e educar 
caracteriza a distância entre a ação da mãe e a do professor, conforme Rodrigues (2017):

Esta aproximação e
distanciamento se
configuram em uma ação
constante na prática da
Educação Infantil e é
elemento básico na
constituição da identidade
de seus profissionais, uma
vez que ao integrar outros
papéis, sua efetivação está
envolta em inúmeras
complexidades
(RODRIGUES, 2017, p.
333).

Nesse contexto, pensar a formação desses profissionais nos mesmos moldes da destinada para as demais etapas da Educação Básica torna-se imprescindível, considerando-se os mais de vinte anos desde que essa foi determinada pela LDB (1996). Rodrigues (2017) considera importante o debate sobre a formação dos professores de Educação Infantil e sobre sua profissionalidade e profissionalização. Para a autora:

$\mathrm{Na}$ medida em que a problematização da especificidade e qualidade da Educação Infantil (creche e também préescola) está direta e intrinsecamente atrelada à discussão das diversas modalidades de formação (inicial, continuada e em serviço) dos profissionais que atuam nesse nível de ensino, independente da nomenclatura que lhes dê (professores, educadores, atendentes, auxiliares, entre outros), tendo em vista que a proficiência da atuação destes profissionais é um dos determinantes no nível de qualidade dos programas de educação de crianças pequenas (RODRIGUES, 2017, p. 334).

Para Freitas (2007) houve uma significativa expansão do ensino superior, na década de 1990, no que se refere aos cursos de formação de professores. Destaca-se a criação dos Institutos Superiores de Educação, além da "diversificação e flexibilização da oferta dos cursos de formação - Normais Superiores, Pedagogia, licenciaturas, cursos especiais e cursos à distância -, de modo a atender à crescente demanda pela formação superior" (FREITAS, 2007, p. 1208).

Freitas (2007, p. 1208) denuncia que a expansão e a flexibilização dos cursos de formação não foram acompanhadas pela qualidade de ensino, pois a ampliação "desenvolveu-se principalmente em instituições privadas sem compromisso com a formação em quaisquer de seus níveis e modalidades". A autora ressalta as centenas de cursos à distância, que chegam a todas as cidades do Brasil, e a retomada de cursos de formação em nível Médio, o que, em sua opinião, oferece condições desiguais nos processos de formação, no caso da $E A D$, e protela a formação superior dos professores em universidades, no caso da formação em nível Médio. Por isso, considera que tais feitos "armadilha das soluções fáceis, ágeis e de "menor custo", que caracterizam, via de regra, as iniciativas no âmbito da educação e particularmente da formação" (FREITAS, 2007, p. 1220).

A preocupação com a qualidade do ensino ofertado nas instituições de Ensino Superior é revelada por Kishimoto (2005) em sua pesquisa sobre os cursos de Pedagogia, em instituições privadas de diferentes estados do Brasil. A autora assinala que a modalidade adotada pela maioria das instituições é composta por um bloco comum de formação, seguido das habilitações, ou seja, a "formação básica contempla de $58 \%$ a $70 \%$ da carga horária do curso, $10 \%$ de estágio e, as habilitações, de $10 \%$ a 16\%" (KISCHIMOTO, 2005, p. 182). Isso evidencia um primeiro dado preocupante, visto que o propósito, ao disponibilizar uma formação comum, é o de possibilitar um leque maior de ofertas, o que resulta em vantagens econômicas para as instituições, porém, há prejuízo no que diz respeito à qualificação profissional para o estudante.

Ao tratar da formação de professores para a Educação Infantil, Kishimoto (2005) ressalta que os currículos dos cursos são ocupados por muitas disciplinas de formação geral do Pedagogo, negligenciando a formação das especificidades. Para a autora as aprendizagens generalizadas "não contemplam o contexto da criança até os seis anos, não focam 
seus saberes, as questões de subjetividade, pluralidade e diversidade culturais, gênero, classe social e etnia" (KISHIMOTO, 2005, p. 182). A pouca valorização do trabalho específico constitui um modelo de curso que reproduz as práticas do Ensino Fundamental e "reitera a antecipação da escolaridade e o descuido com pressupostos de qualidade, como a integração entre o cuidado e a educação" (KISHIMOTO, 2005, p. 183).

Peroza e Martins (2016) afirmam que a não valorização da Educação Infantil, nos processos formativos, se deve ao fato de esta etapa ter sido excluída do campo educacional durante muitos anos. Com a aprovação da LDB de 1996, que exigiu formação dos professores para essa etapa, as instituições formativas passaram a reconhecer e organizar a Educação Infantil a partir de modelos de escolarização próprios do Ensino Fundamental. Para Peroza e Martins (2016, p. 812), esse fato tem consequências até os dias de hoje, "uma vez que as propostas educativas e de formação de professores se fundamentavam nas características das crianças maiores, onde há uma valorização dos aspectos cognitivos sobre as demais dimensões da criança". Segundo as autoras:

$$
\begin{aligned}
& \text { Foi necessário tempo, } \\
& \text { investimento e esforços } \\
& \text { para uma aproximação } \\
& \text { com a realidade das } \\
& \text { práticas educativas com as } \\
& \text { crianças, ampliar e se } \\
& \text { apoderar da } \\
& \text { sistematização desses } \\
& \text { conhecimentos para, } \\
& \text { enfim constituir um } \\
& \text { arcabouço teórico que } \\
& \text { impulsionasse as } \\
& \text { reformulações dos } \\
& \text { currículos dos cursos de } \\
& \text { formação de professores } \\
& \text { para a educação infantil } \\
& \text { (PEROZA; MARTINS, 2016, } \\
& \text { p.819). }
\end{aligned}
$$

Após mais de vinte anos da instituição da Educação Infantil, enquanto primeira etapa da Educação Básica, e do estabelecimento da formação de seus professores, Peroza e Martins (2016) também consideram que a profissionalidade desse docente ainda está em construção. Diante dessa realidade, sugerem que a formação do professor da infância e sua profissionalização sejam fruto de práticas desenvolvidas com as crianças, que valorizem sua realidade e que considerem os saberes de diferentes áreas do conhecimento.

A propósito de todos esses aspectos, fazse urgente uma "verdadeira revolução nas estruturas institucionais formativas e nos currículos da formação" (GATTI, 2010, p. 1375). Já não é mais aceitável consentir com uma formação dúbia, fragmentada e insuficiente para aqueles que são responsáveis pela formação de outros indivíduos. Para que o professor seja capaz de formar sujeitos em sua integralidade, necessita de formação coerente com tal exigência.

A formação de professores
profissionais para a
educação básica tem que
partir de seu campo de
prática e agregar a este os
conhecimentos
necessários selecionados
como valorosos, em seus
fundamentos e com as
mediações didáticas
necessárias, sobretudo por
se tratar de formação para
o trabalho educacional
com crianças e
adolescentes (GATTI,
2010, p. 1375).

Além disso, também não se pode mais admitir que as propostas das instituições formativas e as políticas públicas desconsiderem a importância da formação específica para professores de Educação Infantil e dos primeiros anos do Ensino Fundamental. Faz-se urgente a elaboração de propostas que tenham em vista a valorização desses profissionais, tanto em nível de formação (inicial, continuada e em serviço), quanto em nível de remuneração e condições de trabalho.

Dessa forma, pleiteia-se, para essa profissão, a superação do equivocado status de menos valia e o reconhecimento de que uma profissão que "ensina, deve possuir competência, tenha precisão técnica, rigor filosófico e disciplina metodológica, criatividade e criticidade na forma de entender e trabalhar o conhecimento conforme o contexto em que foi produzido" (ARCE, 2001, p. 182). Uma formação sólida, integrada e específica, tão almejada para os professores da Educação Infantil, torna praticável uma educação de excelência para as crianças de zero a cinco anos de idade. Assim, é por meio dessa formação que deve ser configurado o perfil 
capaz de conhecer e valorizar as características e as necessidades de suas crianças, e a partir desse conhecimento, potencializar as possibilidades para seu pleno desenvolvimento.

\section{CONSIDERAÇÕES FINAIS}

Os avanços da legislação, nas últimas décadas, não foram suficientes para consolidar a universalização da Educação Infantil no Brasil, haja vista que embora a criança seja reconhecida como sujeito de direitos, inclusive o direito à educação de qualidade desde o nascimento, nem todas têm acesso aos serviços prestados. Isso porque, o cumprimento legal vai muito além da oferta de vagas, pois pressupõe o atendimento às especificidades de cada idade, por meio de espaço físico e materiais adequados; proposta pedagógica que respeite os direitos da criança de brincar, se expressar, interagir e aprender; e profissionais qualificados que sustentam sua prática no cuidar e educar.

Por esse motivo a garantia do desenvolvimento profissional e a formação inicial e continuada, é condição primordial para a efetivação de uma educação de mais qualidade, pois há uma relação intrínseca entre os processos formativos e a ação docente no contexto escolar. A formação deve garantir articulação e trabalho coletivo entre os cursos de formação e as escolas infantis, por meio da elaboração e implementação de propostas pedagógicas que possibilitem à criança "apropriação, renovação e articulação de conhecimentos e aprendizagens de diferentes linguagens, assim como o direito à brincadeira e a interação com outras crianças" (BRASIL, 2010, p. 18).

Para tanto, faz se necessário universalizar a Educação Infantil, que deve abarcar a creche e a pré-escola como espaços, eminentemente pedagógicos, que cuidam, educam e acolhem as crianças com base em uma formação mais abrangente dos professores. Para além dessas questões, acredita-se que esse nível de ensino deve ser reconhecido e valorizado como espaço capaz de ampliar o universo infantil, por meio de práticas coletivas, de trocas de experiências e de apropriação de diferentes saberes. Além disso, são necessárias políticas formativas atreladas à valorização social e financeira, bem como a superação da precariedade na preparação didático-pedagógica docente. Desse modo, muitos desafios se impõem frente às determinações legais, sobretudo no que tange à formação e atuação profissional.

\section{REFERÊNCIAS}

ANGOTTI. M. Educação Infantil: para que, para quem e por quê? Campinas: SP: Editora Alínea, 2006.

ARCE, A. Documentação oficial e o mito da educadora nata na educação infantil. Cadernos de pesquisa, São Paulo, n. 113, p. 167-184, jul. $2001 . \quad$ Disponível em: http://www.scielo.br/scielo.php?pid=S0100$15742001000200009 \&$ script $=$ sci abstract $\&$ tIng $=p$ t. Acesso em: 13 maio 2020. DOI: 10.1590/S0100$\underline{15742001000200009}$

BATISTA, R.; ROCHA, E.A. C. Docência na Educação Infantil: origens de uma constituição profissional feminina. Zero-a- seis, Florianópolis, v. 20, n. 37 p. 95-111, jan./jun. 2018.

BRASIL. Presidência da República, Casa Civil, Subchefia para Assuntos Jurídicos. Lei no 5.692, 11 de agosto de 1971. Fixa Diretrizes e Bases para o ensino de $1^{\circ}$ e $2^{\circ}$ graus, e dá outras providências. Brasília, D.F, 11 ago. 1971.

BRASIL. Constituição (1988). Constituição da República Federativa do Brasil. Brasília, DF: Senado Federal, 1988, 305 p. Disponível em: http://www.planalto.gov.br/ccivil_03/constituica o/constituicao91.htm. Acesso em: 8 maio 2020

BRASIL. Ministério da Educação e Cultura. Lei de Diretrizes e Bases da Educação Nacional. Lei no 9394, de 20 de dezembro de 1996. Dispõe sobre as Diretrizes e Bases da Educação Nacional. Brasília, DF: MEC, 1996.

CAMPOS. M. M. FULLGRAF, J.; WIGGERS, V. A Qualidade da educação infantil brasileira: alguns resultados de pesquisa. Cadernos de Pesquisa, São Paulo, v. 36, n. 127, p. 87-128, jan./abr. 2006. Disponível em: https://www.scielo.br/scielo.php?script=sci artte xt\&pid=S0100-

$15742006000100005 \& \operatorname{lng}=p t \&$ tIng=pt. $\quad$ Acesso em: 20 jun. 2020 DOl:/10.1590/S0100$\underline{15742006000100005}$

CAMPOS. M. M. Entre as políticas de qualidade e a qualidade das práticas. Cadernos de Pesquisa, São Paulo, n. 148, p. 22-43, 2013. Disponível em: www.scielo.br/pdf/cp/v43n148/03.pdf. Acesso em: 20 jun. 2020. DOI:/10.1590/S0100$\underline{15742013000100003}$ 
CERISARA, A. B. O Referencial Curricular Nacional para a educação infantil no contexto das reformas. Educação \& Sociedade, Campinas, v. 23, n. 80, p. 326-345, set. 2002. Disponível em: http://www.scielo.br/pdf/es/v23n80/12935.

Acesso em: 05 jun. de 2020. DOI: 10.1590/S0101$\underline{73302002008000016}$

FREITAS, H. C. A. (Nova) política de formação de professores: a prioridade postergada. Educação \& Sociedade, Campinas, v. 28, n. 100 - Especial, p. 1203-1230, out. 2007. Disponível em: https://www.cedes.unicamp.br/. Acesso em: 10 jan. 2020. DOI:10.1590/S0101$\underline{73302007000300026}$

FLORES, M. L. Rodrigues; ALBUQUERQUE, S. S. Direito à educação infantil no contexto da obrigatoriedade de matrícula escolar na préescola. Textura, Canoas, v. 18, n. 36, p. 87-110, jan./abr. 2016. Disponível em: http://www.periodicos.ulbra.br/index.php/txra/a rticle/view/1726/1455. Acesso em: 29 abr. 2020.

GATTI, B. A. Formação de professores no Brasil: características e problemas. Educ. Soc., Campinas, v. 31, n. 113, p. 1355-1379, out./dez. 2010. Disponível em:

http://www.scielo.br/scielo.php?pid=s0101$73302010000400016 \&$ script $=$ sci abstract\&tlng $=p$ t. Acesso em: 12 abr. 2020. DOI:10.1590/S010173302010000400016

HADDAD, L.; CORDEIRO, M. H. ; MONACO, G. L. As tarefas do professor de educação infantil em contextos de creche e pré-escola: buscando compreender tensões e oposições. Educação \& Linguagem, Piracicaba, v. 15 n. 25, p. 134-154. 2012. Disponível em: http://www.bibliotekevirtual.org/index.php/2013 -02-07-03-02-35/2013-02-07-03-03-11/2014-0719-06-15-59/463-el/v15n25/3995-as-tarefas-doprofessor-de-educacao-infantil-em-contextos-decreche-e-pre-escola-buscando-compreendertensoes-e-oposicoes.html. Acesso em: 12 abr. 2020. DOI:10.15603/2176-1043/el.v15n25p134154

KISHIMOTO, T. M. Avanços e retrocessos na formação dos profissionais de educação infantil. In: MACHADO, Maria Lúcia de A. (Org.) Encontros e desencontros em educação infantil. São Paulo: Cortez, 2002. p. 107-115.
MASSUCATO. J. C.; AZEVEDO, H. H. O. Identidade da educação infantil e de seus professores: perspectivas de reconstrução. Seção Temática: Educação Infantil: história, políticas e perspectivas. Revista de Educação PUCCampinas, Campinas, v. 17, n. 2, p. 151-161, jul./dez., 2012. Disponível em: http://periodicos.puccampinas.edu.br/seer/index.php/reveducacao/ar ticle/view/1004/981. Acesso em: 24 abr. 2020.

PASCHOAL, J. D.; BRANDÃO. C. F. Contribuição da legislação para a organização do trabalho pedagógico na Educação Infantil brasileira. Revista HISTEDBR On-line, Campinas, n. 66, p. 196-210, dez. 2015. Disponível em: https://periodicos.sbu.unicamp.br/ojs/index.php /histedbr/article/view/8643710. Acesso em: 10 abr. 2020. DOI: 10.20396/rho.v15i66.8643710

PASCHOAL, J. D. Entre a pré-escola obrigatória e creche opcional: reflexões sobre o direito da criança à educação de qualidade. Rev. HISTEDBR On-line, Campinas, v. 18, n. 3, p. 766-779, jul./set. 2018. Disponível em: https://periodicos.sbu.unicamp.br/ojs/index.php /histedbr/article/view/8651509. Acesso em: 22 abr. 2020. DOI:10.20396/rho.v18i3.8651509

PEROZA, M. A. de R.; MARTINS, P. L. O. A formação de professores para a educação infantil no limiar dos vinte anos da Lei de Diretrizes e Bases da Educação Nacional 9.394/96. Rev. Diálogo Educacional, Curitiba, v. 16, n. 50, p. 809829, out./dez. 2016. Disponível em: http://www2.pucpr.br/reol/pb/index.php/dialog o. Acesso em: 03 fev. 2020. DOl:10.7213/1981416X.16.050.DS01

RODRIGUES, S. A. Mudanças e persistências na formação para docência em creches e préescolas. Rev. Zero-a-Seis, v. 19, n. 36, p. 328-348, jul./dez. $2017 . \quad$ Disponível em: https://periodicos.ufsc.br/index.php/zeroseis/arti cle/view/1980-4512.2017v19n36p328/35622.

Acesso em: 12 abr. 2020. DOI: 10.5007/19804512.2017v19n36p328

SAVIANI, D. Formação de professores: aspectos históricos e teóricos do problema no contexto brasileiro. Revista Brasileira de Educação, Rio de Janeiro, v. 14, n. 40, p. 143-155, jan./abr. 2009. 
Disponível

em:

https://www.scielo.br/scielo.php?script=sci artte xt\&pid=S1413-
$24782009000100012 \& \operatorname{lng}=p t \& t \mid n g=p t . \quad$ Acesso em: 18 dez. 2019. DOI: 10.1590/S1413$\underline{24782009000100012}$ 